\title{
Transition, Flow, and Divergent Times AVINOAM SHALEM
}

Department of Art History, Ludwig Maximilians University, Munich, Germany, and Kunsthistorisches Institut, Florence, Italy;

e-mail: avinoam.shalem@1rz.uni-muenchen.de doi:10.1017/S0020743813000536

The Western academy's growing interest in the contemporary arts in the Arab world illustrates the desire to map "Islam"- problematic as this term is-within the global history of cultures and to integrate it into "Western" models of the writing and documenting of the past. As positive and corrective as these academic approaches may seem, ${ }^{1}$ the notion of recording time - that is, writing history-is still firmly bound at the beginning of the 21 st century to the idea of continuity, and the pattern of "Western"centric thinking imposes that notion upon contemporary artists and art historians. Yet the political changes and spontaneous eruptions that the Middle East and North Africa are experiencing, especially since the beginning of 2011, defy and resist conventional interpretations of historical processes and therefore demand a rethinking of the configuration of the past.

It would be too easy to classify and explain the postmodern renaissance in the Arab world in terms of "in-between" periods and "threshold times," thus integrating the Arab Spring into the idea of continuity and the linearity of time. Indeed, several contemporary artists from the Arab world today are addressing questions of temporalities, mainly by focusing on forward- or backward-looking aesthetics and calling our attention to terms such as tradition, authenticity, and future. Furthermore, the colonial ideology that so profoundly contributed to the making of the imagined Orient in our modern, postcolonial times creates a new dilemma-if not trap-into which artists might indeed fall as they reimagine and reconstruct the "Orient" today. As Walid Raad, a contemporary artist whose work is the focus of this brief discussion, says:

To propose that the Orient is re-imagined invariably brings up the demand to point to whose Orient we are referring ... is it a particular Western (European, American, French, German) construction? If so, which one? Why do we care about this particular construction? Why do we think it exists in the first place? $?^{2}$

In discussing the act of artistic creation, we might discern several patterns of "archiving" historical sequences: one built upon the associative, less accurate, and even erroneous mind; one that is linked to the unconscious and imaginative realms; one based on our wish, or will, to ignore and forget rather than to remember history and past events; or one involving the negation of the idea of the flow of time.

Sometimes the voice of an artist seems to shake, destabilize, or threaten the pillars on which the field of art history rests. The great interest and exposure in the last decademainly through exhibitions - of contemporary artists who were born in, or are linked to, a Muslim-influenced context, or even who produce in a non-Muslim-influenced context, opens new visions for "Islamic" art historians. ${ }^{3}$ A "renaissance" in the art markets, galleries, and museums of the Islamic world raises the questions of which past framework and through which perspective the new birth of artistic creativity should be associated and linked. Islamic art historians' declarations of the death of Islamic 
art, as early as the 16th century and as late as the beginning of the 20th, causes this contemporary art to seem as if it emerges from a vacuum ${ }^{4}$; the last century, the modern, could then be dubbed "the lost century of Islamic art." Walid Raad's work Scratching on Things I Could Disavow: A History of Art in the Arab World / Part 1, Volume 1, Chapter 1 (Beirut: 1992-2005) subtly addresses this matter. ${ }^{5}$ It discusses, aesthetically, the history of art in Lebanon with subtle references to the Lebanese Civil War (1975-90) and the Israeli occupation of Beirut in 1982 that destroyed cultural data (physical and immaterial) and traumatized Lebanese citizens. Walid Raad works like an archaeologist. He scratches on things that he could disavow, and discloses to us the hidden traces, scars, scratch marks, and lacunae in remembering the past and in reimagining the history of Arab art in Lebanon. He writes history with images and text. His history, though, does not claim to construct again the lost memory of the past nor profess truths. On the contrary, Raad's works hesitate, vacillate, and propose to the beholders zones for contemplations (Denkbilder), in which any outcome, thought, or idea is undecidedly built or imagined upon uncertainties.

In one of his poetical images consisting of archival material found in the depots of the bombarded museums in Beirut, we encounter several sheets of paper in pale and faded colors, as if bleached by the sun (see Figure 1). These thin, fragile pages are for Raad like litmus paper. They test the "acidity" of culture and provide him with the physical evidence from which history can be obtained. On their surface, one can trace what Jalal Toufic calls the "withdrawal of tradition past a surpassing disaster."6 Each tiny mark on them, each crease or change of color, and even their faded, crinkled borders tell the story of the injurious process through which Lebanese art has passed. The pages are glued onto the board and organized horizontally according to size, from left to right, smallest to largest. They appear to suggest a quasi-depth to the whole composition, or rather a particular perspective, a particular viewpoint - a way of thinking. Like a historian who organizes evidence in a specific sequence in order to suggest meaning, Raad also hints at a particular prospect of reading these traces on the glued-on paper. Colors replace words, and the spectrum that goes from sharp, almost vitriolic yellow, to a faded light blue tells a story in subtle nuances and betrays, or rather misleads, us into reading it in a linear, evolutionary manner. A vertical contour composed of three relatively large pages suggests a transmission from a faded light blue page at the top to a misty, foggy light gray at the bottom. The page in the center of this vertical contour is marked by a sharp and angular line. It appears as a scar. And yet, our gaze comes to rest on it. We gravitate toward thinking that this clear line provides a source of stability, and we grasp it as if for an anchor amidst a sea of opaque, blurred rectangular spaces swimming in a fluid vacuum. Raad suggests to the viewer a specific aesthetic condition; his installations seem like memorial rooms of a vanished tradition.

Raad's works are most revealing in their critical approach to time and memory. Like him, we are bound to work within the parameters of the ideologically constructed history of the region and the manipulated cultural vacuum that was deliberately created by manifold ideologies. The remnants of varied layers of "truths" and histories_imagined or contrived-and manipulated crucial moments are collected and exhibited like relics of devastating wars. Raad talks with the dead and tells the story of a dissolving world. The vacuum of local culture is exposed, the flesh has been ripped off, and white bones are now being collected. 

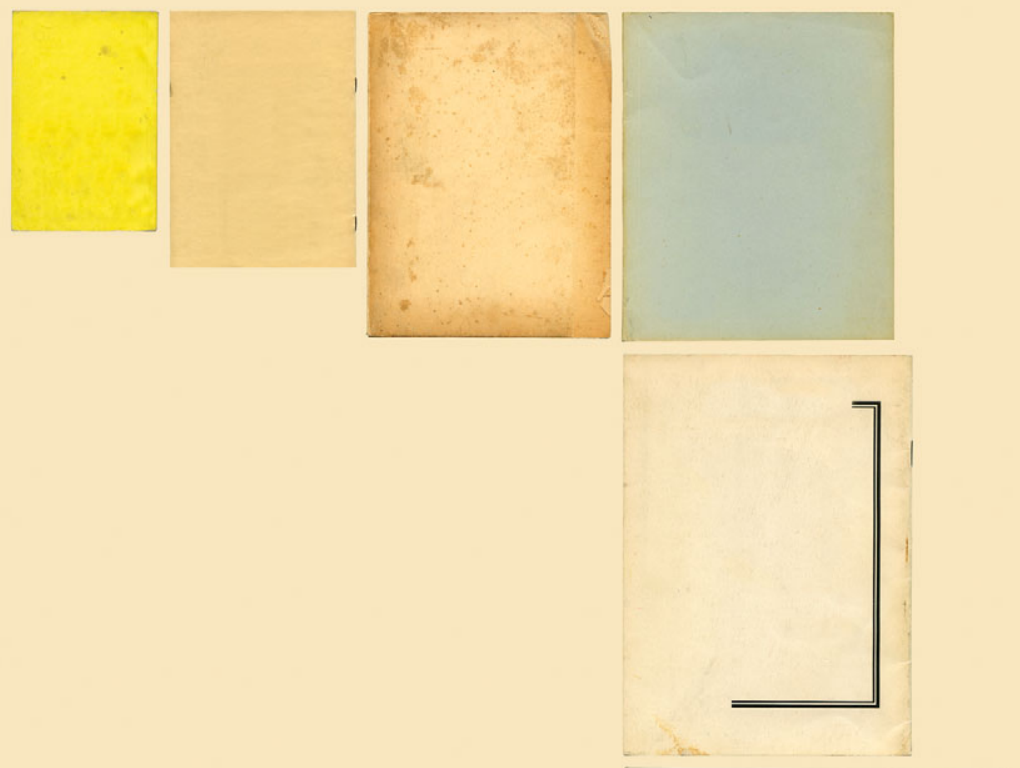

FIGURE 1. Appendix XVIII, Plate 92 (A History of a Monograph), 2008. Color photograph (16.5 × 21.5 in.). Copyright Walid Raad. Reprinted with permission.

\section{NOTES}

${ }^{1}$ See, for example, Samir Amin, Global History: A View from the South (Bangalore: Books for Change, 2011); Tamim Ansary, Destiny Disrupted: A History of the World through Islamic Eyes (New York: Public Affairs, 2009); and Jane Burbank and Frederick Cooper, Empires in World History: Power and the Politics of Difference (Princeton, N.J.: Princeton University Press, 2010). For "corrections" in the field of art history, see 
esp. Thomas DaCosta Kaufmann, "Eurocentrism and Art History? Universal History and the Historiography of the Arts before Winckelmann," in Memory and Oblivion, ed. Wessel Reinink and Jeroen Stumpel (Boston: Springer, 1999), 35-42; and Rasheed Araeen, "Eurocentricity, Canonization of the White/European Subject in Art History, and the Marginalisation of the Other," in Globalisierung / Hierarchisierung. Kulturellen Dominanzen in Kunst und Kunstgeschichte, ed. Irene Below and Beatrice von Bismarck (Marburg, Germany: Jonas Verlag, 2005), 54-61.

${ }^{2}$ Walid Raad, 1 January 1995, cited in Jayce Salloum, “. . . east of here ... (upon arrival),” in East of Here: (Re)imagining the “Orient,” ed. Jayce Salloum, exh. cat., YYZ Gallery, Toronto, 20 November-14 December 1996 (Toronto: YYZ Artists’ Outlet, 1996), 4-5.

${ }^{3}$ See esp. the debate around the exhibition Without Boundary: Seventeen Ways of Looking, held at New York's MOMA in 2006. Fereshteh Daftari, ed., Without Boundary: Seventeen Ways of Looking, exh. cat. (New York: Museum of Modern Art, 2006). For an interesting interview on the status of artists working today in the so-called off-main Western centers, see Lilian Engelmann and Vera Lauf, "Rediscovering the Dialogue: An Interview with Rasheed Araeen," in Below and Von Bismarck, Globalisierung / Hierarchisierung, 62-64.

${ }^{4}$ On this issue of the "life span" of Islamic art and the problems concerning its methodology, see esp. the articles of Barry F. Flood, Nasser Rabat, Avinoam Shalem, and Wendy Shaw, in the recent special issue "Islamic Art Historiography," ed. Margaret Graves and Moya Carey, Journal of Art Historiography 6 (June 2012), http://arthistoriography.files.wordpress.com/.

${ }^{5}$ See esp. Kara L. Rooney's article in The Brooklyn Rail, http://www.brooklynrail.org/2009/12/artseen/ walid-raad-scratching-on-things-i-could-disavow-a-history-of-art-in-the-arab-worldpart-1-volume-1-chapter-1beirut-1992-2005 (accessed 7 March 2013); and Barbara Casavecchia's article on Walid Raad in Frieze, http://www.frieze.com/shows/review/walid_raad/ (accessed 7 March 2013).

${ }^{6}$ Jalal Toufic, Forthcoming (Berkeley, Calif.: Atelos, 2000), esp. 64-68. On this question concerning the production of art in Lebanon today, see Hannah Feldman and Akram Zaatari, "Mining War: Fragments from a Conversation Already Passed," Art Journal (2007): 49-67. See also Hanan Toukan, "Art, Aid, Affect: Locating the Political in Post-Civil War Lebanon's Cultural Production" (PhD. diss., School of Oriental and African Studies, 2012). 